\title{
An Expert System to Assist Businesses in Financial Decision Making to Enhance Efficiency
}

\author{
Fuseini Inusah \\ Bagabaga College of Education, Tamale, Ghana \\ Department of Mathematics and ICT, Tamale, \\ Ghana
}

\begin{abstract}
This research proposes developing an expert system to assist businesses in financial decision making. It is a more technological means of storing and using the knowledge of the human expert. This helps in minimizing cost and inconveniences in hiring experts. No business can survive without effective and efficient management. The major activity in management is decision making. The efficiency of management in decision making is based on speed, accuracy and how easy it is for the decisions to be implemented. This is a herculean task for an average expert. As an exploratory research, the responses of all the fifteen (15) managers were carefully analyzed to get a solution to the problem. With a target of using one day in making a decision, only sixty percent $(60 \%)$ of human decisions were accurate whiles hundred percent $(100 \%)$ of the decisions on expert systems were accurate. The speed of the human expert is one (1) decision for every seven (7) days representing 0.14 decisions per day whiles that of the expert system is one (1) decision per day. Only two (2) decisions out of every five (5) decision of the human decision were easy to implement while all the five (5) decisions were easy to implement using the expert system due to the clarity and consistency in its results. The cost of hiring the human expert and the bureaucracy in decision making can be eliminated if an expert system is used. Also, interoperability (systems developed to pick data automatically from other systems) minimizes the errors in data entry.
\end{abstract}

\section{General Terms}

Expert system, Decision making, Prototype, knowledge base, Inference engine, Manual computations, Accounting ratio.

\section{Keywords}

Expert system, Expert verse Human System, Decision Making, Efficiency

\section{INTRODUCTION}

Decision making is a very important aspect of business operation. There cannot be effective management of business without accurate decisions taken. Many businesses lack the ability to come out with fast and error free decisions which are easy to implement to enhance more efficiency. The case is serious when talking about trading businesses. Financial decision making demands a lot of accuracy in other to enhance maximum use of the limited resources of a business. The human aspect of decision making makes it difficult for the business to achieve more efficiency and effectiveness. This is because of the bureaucracy in decision making coupled with the inaccuracy and inconsistency in the results by humans in decisions.

All expects of management can be achieved by the use of expert system in decision making. Expert systems can help eliminate if not completely eradicate the challenges posed by the human factor in decision making. The use of expert

\author{
Anokye Acheampong Amponsah \\ University of Energy and Natural Resources \\ Department of Computer Science and Informatics
}

System will help in enhancing more accuracy, speed and ease of use of the results generated. This will also bring consistency in the results when given the same conditions. Under the field of financial management, figures are often used to compute results and the results are interpreted to arrive at a decision. These computations need more accuracy to eliminate errors that can affect the results of the decision. Manual computation is characterized by errors associated with the human factor and this challenge must be addressed.

\section{RELATED WORK}

Experts are people who have talents in special areas or fields. They are integrated and have a wider scope of knowledge. Experts are critical thinkers in their fields of expertise and can reason to provide relevant solutions to problems. They have facts on knowledge of the field and can analyze and synthesize information in their fields of expertise [1]. If a system can mimic the expertise of the human expert, then it is an expert system.

Proposed mobile medical expert system to enhance efficiency and effectiveness of health workers in Komfo Anokye Teaching Hospital was made in Ghana. This proposed system was to help doctors to increase the number of patients they can attend to in a day and also reduce the long queues that are often experience in the hospital. "This paper introduced and proposed a Mobile Medical Expert System (mMES) using mobile devices and computing technology so that Medical Doctors in Ghana can speed up diagnosis, confirm their own diagnosis, provide advice on found diagnosis and provide advice on certain diseases when diagnosed on a patient."[2]

According to Yanqing using expert system in decision making scrutinizes three aspects that have relationship in the use of expert systems for decision making in organizations. It consist of Expert System effectiveness if used to assist or replace human decision, the user attitude towards Expert System and, the willingness of organizations to accept Expert System at various levels of management. Business game environment was used as a research based for the development of the system within a simulation of a manufacturing company. Anthony's three levels of decision making was used to come out with (EXGAME) which was developed based on a formation to manage the simulated company using business game without much user intervention. For this aspect, another system (ADGAME) was advisory system added for better decisions to manage the game company. These two systems are integrated to perform different roles and achieve one function. ADGAME was different from EXGAME, not just by an extension of it. A comparison of EXGAME and human rivals was done by evaluating its result. User performance and analyses of views was done using ADGAME as a helpful decision making aid. It was realized that the expert system can easily replace the operational manager but there were challenges when used for strategic management. It also 
revealed the prospect of the entire organization accepting Expert Systems in the selected company.[3]

MYCIN was developed by Stanford in 1970 to diagnose infectious diseases. In this medical diagnosis system, symptoms description by user to the computer as they would do to a doctor is done and the computer returns a medical diagnosis [4].

Still in 1970, MIT developed an expert system by name MACSYMA which was a math expert system[5].

A solution to voice recognition through an expert system's approach in 1970 was also done through Hearsay. It was developed by Carnegie Mellon for speech recognition. However, majority of the components for this type of expert systems was not all that successful. It was more a pattern recognition system detecting patterns in noisy data. In this, phonemes recognition in audio stream and other early examples were analyzing sonar data to detect Russian submarines [6].

In 1977, Stanford Research institute developed PROSPECTOR for mineral diagnosis. İt was meant for interpretation by inferring situation descriptions from sensor data [7] .

Assessment of students with multiple disabilities was also done using SMH.PAL [8].

In Italy in the 1990's, Ismes developed an expert system by name Mistral to monitor dam safety. This automatically received data from a system for monitoring and performs diagnosis of the state of the dam. As a registered trade mark for CESI, It has been installed on several dams in the country and even abroad and also on landslides under Eyelet, and on monuments under Kaleidos [9].

The above mentioned expert systems had inference engine and consultation environments. However, the availability of a multiple alternatives to get results and the provision of links to connect to external data sources for more information and for research is not available in those systems. This is considered in the system developed.

An Expert System basically has two aspects; the environment for developing and another for consultation. The developer uses the development environment to make changes to the system whiles the user uses the consultation environment to obtain knowledge or advice. It is the consultation environment which is thought of as an Expert System. Some components of expert system are; Subsystem for knowledge acquisition, Inference engine, Explanation subsystem, Knowledge base, User interface, Blackboard, Knowledge refinement subsystem and Optional Database [10].

There are three components of the experts system that the user interacts with; the user interface, inference engine and the stored expertise.

The user of an Expert System can be an evaluator, a teacher, a learner, or a customer. User Interface style could be command line, menu-driven, question and answer, natural language or graphics interface. User interface conveniences are designed to recognize the type of user and the level of the user's expertise in transaction.

Interoperability among systems is often enhanced by the used of Expert System. An Expert System may receive input from an online data source (database, text file, web page, etc.). It may be used to monitor a physical system, in which case input may come directly from sensing devices. An Expert System may also be used to control a physical system, in which case output will be signals to the system[11]

Care must be taken in selecting the knowledge representation scheme which is essential. Basically, problem solving is the value of the knowledge base and also on the inference method used. It is the bank of basic knowledge. The architecture of knowledge representation scheme affects the design of the expert system and the overall efficiency of the system.

Business expert systems are an aspect of artificial intelligence that aims at using the computer to mimic human expertise. This system is consulted in the same way as human expert is consulted to gain advice. The user poses specification problem to the expert system. Like the human, further questions may be asked by the system to gain more information in other to produce accurate result to solve the problem posed[12]. Stored component of an expert system can be seen as conditions in the form of rules. These rules can satisfy conditions as true or false and produces some conclusions as valid [13]. The inference engine is the attempt to solve the problem. It can explain to the user of the system why some conclusions are drawn upon request.

\subsection{Structure of Decision Making}

Depending on the type of organization and the nature of the decision to be made, a decision can be made by a group or an individual. It can also be made by higher level executives or lower level workers. It may be made based on the expertise of the people or person involved. Different organizations have different policies in decision making. Whereas there are boards to handle decisions in some organizations, other organizations do make decisions based on just the expertise of those involved[14]

In some business organizations, the right to form part of the decision making body depends on the contributions or ownership right the person possess. Also, the right to vote depends on the degree of ownership a person has in the organization. This is because the capital used in running the business will be affected if the wrong decision is made hence the need for the highest contributors to decide their own destiny. All this factors must be taken into consideration when making decisions.

The use of expert systems however does not go through those structures. The nature of the decision is determined by the expert system with reference to the conditions set for the generation of results. This makes decision making using expert system fast, simple, accurate and very easy to use.

\subsection{Critical factors that affects personal interest}

The human system of decision making has a lot of influences that may affect the results of a decision. The expert system can help in minimizing some of those influences. The following are the various influences in human decision making.

Selectively searching for evidence or confirmation bias is an influence in human decision making. The interest of a person may be more on getting facts to support certain conclusions than facts that support different conclusions [15].

Premature ending of search for evidence can also influence human decision making. People easily take the first attempt that looks like it might work. 
Cognitive inertia refers to unwillingness to change existing thought patterns when facing new circumstances. This also affects results in decision making [16].

Selective perception is also another influence. People quickly eliminate facts that they do not consider vital [17]

Wishful thinking is the zeal to see things in a certain - usually positive - light; this can distort views and thinking [18].

Choice-supportive bias occurs when people disorganize their ability to remember chosen and rejected options to make the chosen options seem more attractive.

Recent events (occurrences) make people concentrate on more recent information and either ignore or forget more distant information. The reciprocal is primacy effect in first set of data[15].

Repetition bias is a feeling that what one has been told most often and by the greatest number of different sources is the right information.

Anchoring and adjustment is another influence. Initial information shapes our view of subsequent information. This also affects decision

Groupthink is peer pressure making one conform to the view held by the group. This also influences a person's judgment in making decisions.

Source credibility bias is unwillingness to accept a person's statement on the basis of not liking the person, organization, or group to which the person belongs. For comfort people accept statements by others that they like.

Incremental decision-making and rising commitment is an influence. Looking at a decision as just a step in a process affects a series of similar decisions. Zero-based decisionmaking can be contrasted with this.

In Attribution asymmetry, People associate their achievement to internal factors such as abilities talents and external factors such as bad luck. The opposite is shown when people explain others' success or failure.

Role fulfillment refers to the ability to conform to other people's decision-making expectations.

Underestimating doubt and the magic of controlling issues, the future do not border people as they believe they will have more control over events than they really.

Framing bias is best rejected by increasing the numbers and presenting data in several formats [19].

Sunk-cost fallacy is a specific type of enclosing effect which can influence decision. It involves a person taking a stand about a current situation because of earlier investment made [20].

Prospect theory contains the believe that when one is facing a decision event, the individual is likely to accept risk when evaluating possible losses, and is likely to do away with risks when assessing potential gains[20]. This has influence on decision-making if the situation involves a threat, or opportunity.

Optimism bias has to do with overestimating the events of positive events occurring in the future and underestimating the situation of negative life events [21]. These unfair anticipations are produced and maintained in the face of counter evidence. This is through likelihood to reduce undesirable information. An optimism bias can change risk perception and decision-making in many domains. This can range from finance to health.

All the above influences if not properly handled by the human expert, can affect the results of decision making. This however will be eliminated when an expert system is used.

\subsection{Financial Decisions}

Transactions are recorded into the books of accounts for record keeping and for analysis for interpretation in future. Books of accounts are balanced at the end of an accounting year to know the final figures for each account. These balancing figures are used to draw a trial balance to determine the accuracy of the entries made. The balancing figures used in drawing the trial balance are used for the preparation of final accounts. These accounts include the trading, profit and loss accounts and the balance sheet to know the financial position of the business [22].

The final accounts are used in the calculation of the accounting ratios for the business. These ratios are interpreted for decision making with reference to other conditions available. This is use to show the financial position of the business. This therefore means that accuracy, clarity and completeness in recording financial transactions are necessary to assist in making decisions[23].

\subsubsection{Accounting Ratios Analysis}

Interpreting financial statements has to do with identifying the strength and weaknesses of a firm financially by properly establishing the relationship between or among the items of the trading, profit and loss account and the balance sheet. Accounting ratios are to show the relationship between or among accounting figures expressed mathematically. It is used as mechanism for evaluating the financial position and performance of a business.

Ratio analysis is important to those who use accounting information for evaluating the performance and financial position of a business. It converts figures into meaningful comparable forms and facilitates making inferences about absolute figures. Ratio analysis concentrates on the operating business efficiency, liquidity of the business, profitability, the capital structure and stock exchange indicators in a significant manner. They are widely used by users of accounting information. Specifically, accounting ratios may be used to; 1 . Provide means to showing the interrelationship between groups of figures and can be used as a measure of efficiency. 2. Helps in summarizing large volume of data. 3. Forecast and plan, 4. Serve as aid to communication as changes in the operations of the business can be seen. 5. Evaluate the performance of the business. 6. It assess how effective the entity is in achieving objectives previously established by its management, members, shareholders, board of directors and all the users of accounting information. 7. Assess the economic strengths and weaknesses of the business. 8 . Determine the liquidity of the business. 9. Predict the future of the entity including the ability to pay dividends and other cash out flows.10. Attest to compliance with company laws and other legal obligations etc.[22].

\section{METHODOLOGY}

This exploratory research employs both experimentation and case study to solve the problem. It combines the use of IT in experts systems under Artificial Intelligence(AI) and investigation through research. Prototyping is the design methodology adopted in designing the system since the domain experts(management) have to continue interacting with the system and provide suggestions for the system to be 
fully developed. The process for prototyping has four steps. The model adopted is shown in figure 3

\subsection{System Design methodology}

After the various research instruments were used in investigating into the problem, a system was design to address the problem. Prototyping as a system development methodology was used in getting the system develop on time to meet the requirements. The nature of the problem and the type of domain experts used compelled the researcher to choose the evolutional prototype instead of the traditional System Development Life Cycle (SDLC). The requirements were not clear as the business wanted some elements or components to be added for their own convenience. Also the Microsoft Office Excel 2013 was used as expert development package software because the already existing systems of the business were in that format and the business will like to be consistent in software. Links to the already existing applications to the expert system was also emphasized on to enable in interoperability among the systems.

\subsection{Stages in Prototyping}

Four sequential stages were considered in developing the system using prototyping as a design methodology. The stages are:

1. Identifying the basic requirements

2. Developing the initial prototype

3. User reviewing

4. Revising and enhancing the prototype

The system development team was made up of the researcher who was the knowledge engineer and the managers as domain experts. This team developed the system using the four stages in prototyping. The flow chart for the various stages is seen below.

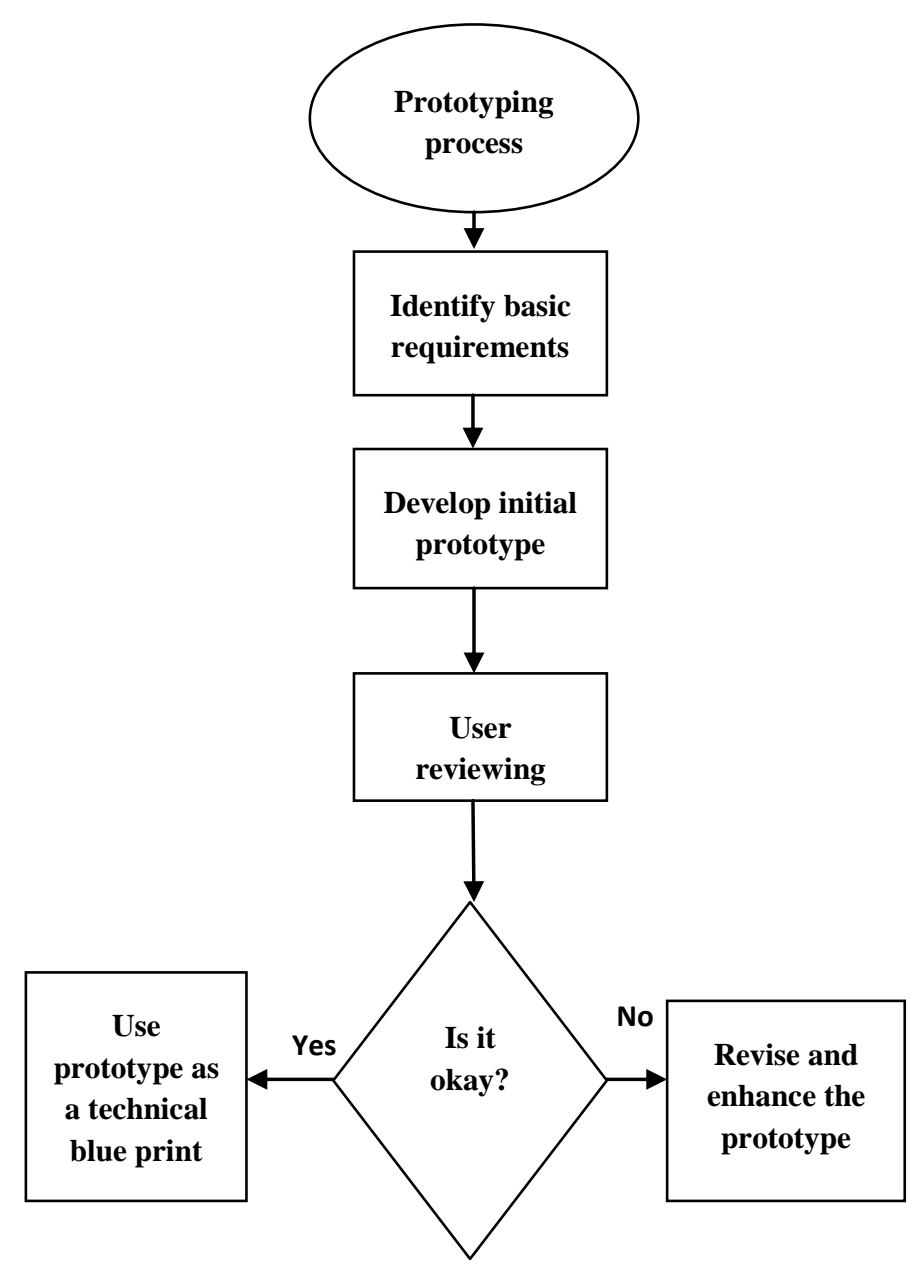

Figure 1 Flowchart of the Prototyping Process Adopted

After this model was adopted, the actual system development was done. Requirements were gathered for the system development to solve the problem identified. The requirements were carefully identified. Figure 4 shows the flowchart 


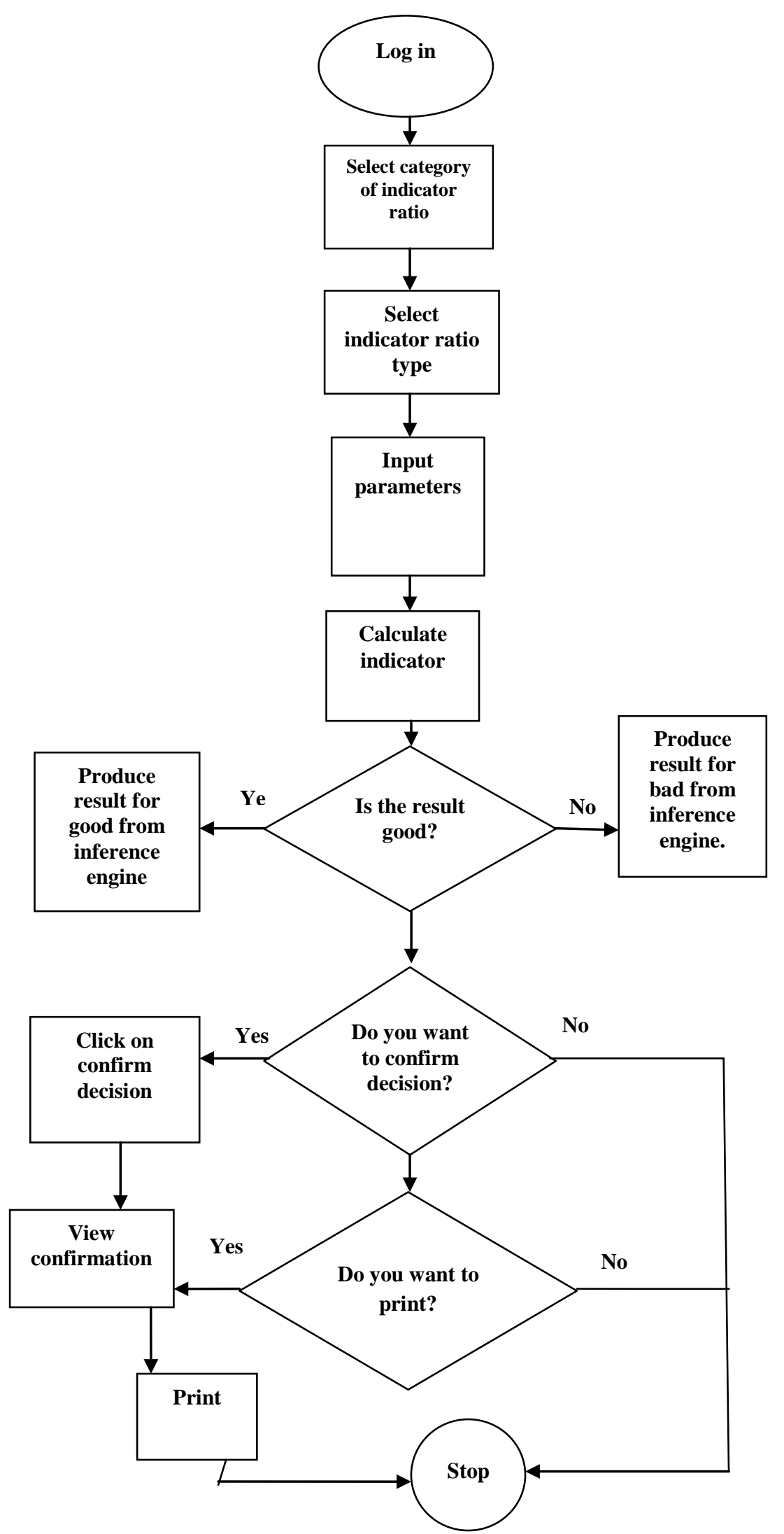

Figure 2: Flowchart for the System Development

\subsection{Population of the Study}

The target group for the research was the management of Quality First Company Limited in the Tamale Metropolis in Ghana. The population is made up of all management. The total management staff is fifteen (15) managers. For effectiveness and reliability of the results, the entire population of the management was captured in gathering the data. Measures were taken to give equal chance to members 
of the population to be captured. Five (5) managers were selected as leaders due to the tedious nature of qualitative aspect of the data in the research.

\subsection{Sampling Design}

All the fifteen (15) managers were considered as sample for the research. This is because of the small nature of the population involved. The sampling technique was necessary to ensure that each member of the population gets equal chance of selection.

\subsection{Research Instruments}

In this research, observation, interview, document analysis and expert consultations are used as means of getting information. Instruments that were used are; observation guide, interview guide and the financial record books or entries of the organization. These instruments were tested by the researcher before been used. Students in the Business School in the Kwame Nkrumah University of Science and Technology were used in testing these instruments.

\subsection{Data Analysis}

After the above instruments were used to gather data for the research, various analysis of the data gathered was made. Both qualitative and quantitative nature of the data gathered called for detail analysis of the data. The various responses of the respondents were looked at and grouped base on similarities. Four different steps were used in getting the information. The steps are;

1. Collection of broad ideas given by respondents

2. Identifying the number of times an idea re-occurs within interviews and observations made at research center.

3. Classifying main ideas

4. Integrating main ideas.

After the above steps were used, the researcher quantified the responses and tabulated it to rank the responses given by respondents in order of importance or priority. This was necessary to know the degree of effect on such responses on the efficiency in decision making using the developed expert system.

\section{PRESENTATION AND DISCUSSION OF RESULTS}

The results of the research has been grouped into two(2) aspects. The data gathered before system development and data gathered after system development. Below is a careful representation of the data analysed.

Table 1 Results of the Interview on the Efficiency of Expert System.

\begin{tabular}{|l|l|l|l|}
\hline Question & Yes & No & Undecided \\
\hline $\begin{array}{l}\text { Is your company fast in } \\
\text { decision making? }\end{array}$ & 11 & 0 & 4 \\
\hline $\begin{array}{l}\text { Do you follow the laid down } \\
\text { procedures in decision making? }\end{array}$ & 7 & 5 & 3 \\
\hline Are your decisions accurate? & 11 & 1 & 3 \\
\hline $\begin{array}{l}\text { Do you find it easy making a } \\
\text { decision? }\end{array}$ & 13 & 0 & 3 \\
\hline $\begin{array}{l}\text { Does the system help in } \\
\text { avoiding personal interest in } \\
\text { decisions? }\end{array}$ & 11 & 1 & 3 \\
\hline
\end{tabular}

Are you satisfied with the result

of the decisions?

Table 2 Results for the Observation Comparison of Human and Expert System.

\begin{tabular}{|l|l|l|l|}
\hline Description of activity & $\begin{array}{l}\text { Human } \\
\text { decision }\end{array}$ & $\begin{array}{l}\text { Expert } \\
\text { system }\end{array}$ & Variance \\
\hline $\begin{array}{l}\text { Number of days for a } \\
\text { decision }\end{array}$ & 7 & 1 & 6 \\
\hline $\begin{array}{l}\text { Speed (number of } \\
\text { decision/days) }\end{array}$ & 0.14 & 1 & 0.86 \\
\hline Percentage speed & 14.3 & 100 & 85.7 \\
\hline
\end{tabular}

Table 3 Comparison of Results for Interview on Human and Expert System

\begin{tabular}{|l|l|l|l|}
\hline Description of activity & $\begin{array}{l}\text { Human } \\
\text { expert }\end{array}$ & $\begin{array}{l}\text { Expert } \\
\text { system }\end{array}$ & Variance \\
\hline $\begin{array}{l}\text { Number of accurate } \\
\text { result out of five decision }\end{array}$ & 3 & 5 & 2 \\
\hline Percentage accuracy & 60 & 100 & 40 \\
\hline
\end{tabular}

Table 4 Results on the Observation of Expert System

\begin{tabular}{|l|l|l|l|}
\hline Aspect observed & \multicolumn{2}{|l|}{ Degree of satisfaction } \\
\hline & High & Moderate & Low \\
\hline $\begin{array}{l}\text { Ability of expert system to } \\
\text { make decision }\end{array}$ & $\sqrt{ }$ & & \\
\hline Speed of decision making & $\sqrt{ }$ & & \\
\hline Accuracy of decisions & $\sqrt{ }$ & & \\
\hline $\begin{array}{l}\text { Ease in decision making } \\
\text { Avoiding interest and emotion } \\
\text { of individuals in decision } \\
\text { making }\end{array}$ & $\sqrt{ }$ & & \\
\hline $\begin{array}{l}\text { Avoiding interest and emotion } \\
\text { of individuals in decision } \\
\text { making }\end{array}$ & $\sqrt{ }$ & & \\
\hline $\begin{array}{l}\text { Achievement of result after } \\
\text { implementation }\end{array}$ & $\sqrt{ }$ & & \\
\hline Flexibility in getting a solution & $\sqrt{ }$ & & $\sqrt{ }$ \\
\hline $\begin{array}{l}\text { Ability to learn from } \\
\text { environment }\end{array}$ & & & $\sqrt{ }$ \\
\hline Power of creativity & & & $\sqrt{ }$ \\
\hline
\end{tabular}


Table 1 Results on the Observation on Consistency on Decision Making

\begin{tabular}{|l|l|l|}
\hline Aspect & $\begin{array}{l}\text { Expert } \\
\text { System }\end{array}$ & $\begin{array}{l}\text { Human } \\
\text { Decision }\end{array}$ \\
\hline Speed of decision making & HIGH & Low \\
\hline Accuracy of decisions & HIGH & Moderate \\
\hline Ease in decision making & HIGH & Moderate \\
\hline $\begin{array}{l}\text { Avoiding interest of individuals in } \\
\text { decision making }\end{array}$ & HIGH & Low \\
\hline $\begin{array}{l}\text { Achievement of result after } \\
\text { implementation }\end{array}$ & HIGH & Moderate \\
\hline Flexibility in getting a solution & Lack & HIGH \\
\hline Ability to learn from environment & Lack & HIGH \\
\hline Power of creativity & Lack & HIGH \\
\hline
\end{tabular}

Table 6 Results on Observation On Consistency on Decision Making

\begin{tabular}{|l|l|l|l|}
\hline Description of Activity & $\begin{array}{l}\text { Human } \\
\text { Expert }\end{array}$ & $\begin{array}{l}\text { Expert } \\
\text { System }\end{array}$ & Variance \\
\hline $\begin{array}{l}\text { Consistent and easy to } \\
\text { implement decisions } \\
\text { out of five }\end{array}$ & 2 & 5 & 3 \\
\hline $\begin{array}{l}\text { Percentage consistent } \\
\text { and easy to implement }\end{array}$ & 40 & 100 & 60 \\
\hline
\end{tabular}

\section{Findings}

1. The human decision making has an accuracy of only sixty percent $(60 \%)$ whiles hundred percent $(100 \%)$ accuracy is guaranteed in expert system.

2. The bureaucracy in decision making which consumes a lot of resources and introduces latency to the decision making process can be eliminated if an expert system is used in decision making. The inaccuracy, ambiguity, inconsistency, and the interests of management in decision making can all be eliminated.

3. The expert system cannot completely replace the human system but can assist management in making decisions to enhance efficiency.

\section{CONCLUSION}

Maximum efficiency can be enhanced if experts systems are used in assisting management in financial decision making. The problem of management spending longer periods in making a decision in the company will now be a thing of the past. Accuracy of the results in decision making is guaranteed and decisions will now be free from ambiguity and inconsistency. In short, the use of expert system in decision making eliminates errors in accounting and also enhances more efficiency in decision making.

\section{REFERENCES}

[1] Jackson, Peter (1998), Introduction To Expert Systems (3 ed.), Addison Wesley, p. 2, ISBN 978-0-201-87686-4

[2] Nana Yaw Asabre (2012) A Mobile Medical Expert System for Health Institutions in Ghana, International Journal of Science and Technology (2 ed) p333-344 ISSN 2224-3577
[3] Duan, Yanqing (1993). The use of expert systems for decision making in organizations. $\mathrm{PhD}$ thesis, Aston University.

[4] Buchanan, B.G.; Shortliffe, E.H. (1984).Rule Based Expert Systems: The MYCIN Experiments of the Stanford Heuristic Programming Project. Reading, MA: Addison-Wesley. ISBN 978-0-201-10172-0.

[5] Moses Joel, Macsyma: A Personal History. Invited Presentation in Milestones in Computer Algebra, MIT (May 2008) page 2-7

[6] Lee D. Erman, Frederick Hayes-Roth, Victor R. Lesse, D. Raj Reddy (1988). The Hearsay-II SpeechUnderstanding System: Integrating Knowledge to Resolve Uncertainty. Blackboard Systems, page. 31 - 86

[7] Brian S.Everitt, the (2011) ristopher PaCh PROSPECTOR system for mineral exploration Menlo Park: Stanford Research Institute Final Report, Project 8172. ... Slocum, J. and Sutherland, G. L. 1977: Development of a computer-based consultant for mineral exploration. Experimental computer-based diagnostic consultant for general internal medicine.

[8] Alan, Hofmeister (1994). "SMH.PAL: an expert system for identifying treatment procedures for students with severe disabilities.".Exceptional Children 61 (2).Retrieved 30 November 2013

[9] Salvaneschi, Paolo; Cadei, Mauro; Lazzari, Marco (1996). "Applying AI to structural safety monitoring and evaluation". IEEE Expert - Intelligent Systems. 11 (4): 24-34. doi:10.1109/64.511774. Retrieved 5 March 2014.

[10] Smith, Reid (May 8, 1985). "Knowledge-Based SystemsConcepts,Techniques,Examples"(PDF).http://w ww.reidgsmith.com.Schlumberger-Doll Research.Retrieved 9 November 2013.

[11] Leondes, Cornelius T. (2002). Expert systems: the technology of knowledge management and decision making for the 21 st century. page 1-22. ISBN 978-0-12443880-4.

[12] W. B. Rauch-Hindin, Artificial Intellisence in Business. Science, and Industrv, Prentice-Hall, Englewood Cliffs, New Jersey, 1986.

[13] C. W. Holsapple and A. B. Whin- ston, Manauer's Guide to ExvertSvstemsUsins Guru, Dow Jones- Irwin, Homewood, Illinois, 1986.

[14] Amita, Etzioni, Humble decision making, harvard business review. 1989, page 122-126

[15] Plous, Scott (1993), The Psychology of Judgment and Decision Making, p. 233

[16] Hodgkinson, Gerard P. (1997-11-01). "Cognitive Inertia in a Turbulent Market: the Case of UK Residential Estate Agents". Journal of Management Studies. 34 (6): $921-$ 945. doi:10.1111/1467-6486.00078. ISSN 1467-6486.

[17] Steven Lucas Counselling. (2009, December 29). Psychology Definition Of The Week: Selective Perception. Retrieved March 18, 2013,

[18] Chua, E. F.; Rand-Giovannetti, E.; Schacter, D. L.; Albert, M.; Sperling, R. A. (2004)."Dissociating confidence and accuracy: Functional magnetic resonance imaging shows origins of the subjective memory 
experience" (PDF). Journal of Cognitive Neuroscience16 (7):page 1131-1142. doi:10.1162/0898929041920568. PMID 15453969

[19] Perneger, Thomas V.; Agoritsas, Thomas (December 2011). "Doctors and patients' susceptibility to framing bias: a randomized trial". Journal of General Internal Medicine26 (12):page 1411-1417. doi:10.1007/s11606011-1810-x. PMID 21792695

[20] Schacter, Daniel L.; Gilbert, Daniel Todd; Wegner, Daniel M. (2011) [2009]. Psychology (2nd ed.). New York: Worth Publishers. ISBN 9781429237192.OCLC 755079969.
[21] Sharot, Tali (2011). The optimism bias: a tour of the irrationally positive brain (1st ed.). New York: Pantheon Books. ISBN 9780307378484.OCLC 667609433.

[22] Ebenezer NyakorAssabil (2008) Ascertain guide. Financial accounting for beginners in tertiary institution. Page 295-300

[23] Weston. H, Agor, the logic of intuition: how top executives make important decisions, organizational dynamics, 14, 1986, page 5-18 